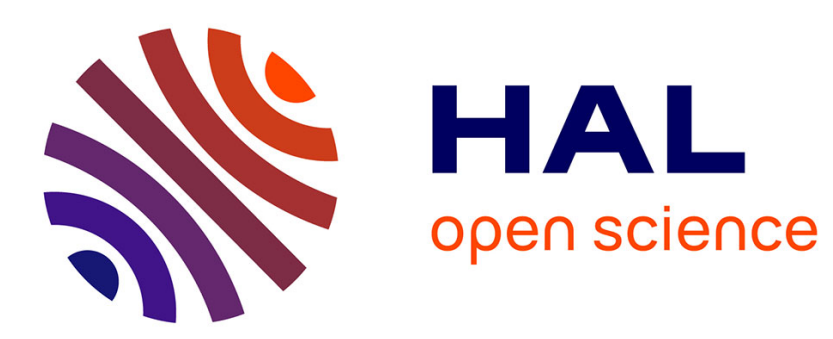

\title{
Food insecurity and mental health problems among a community sample of young adults
}

Laura Pryor, Sandrine Lioret, Judith van Der Waerden, Éric Fombonne, Bruno Falissard, Maria Melchior

\section{To cite this version:}

Laura Pryor, Sandrine Lioret, Judith van Der Waerden, Éric Fombonne, Bruno Falissard, et al.. Food insecurity and mental health problems among a community sample of young adults. Social Psychiatry and Psychiatric Epidemiology, 2016, 51, pp.1073. 10.1007/s00127-016-1249-9 . hal-01332602

\section{HAL Id: hal-01332602 https://hal.sorbonne-universite.fr/hal-01332602}

Submitted on 16 Jun 2016

HAL is a multi-disciplinary open access archive for the deposit and dissemination of scientific research documents, whether they are published or not. The documents may come from teaching and research institutions in France or abroad, or from public or private research centers.
L'archive ouverte pluridisciplinaire $\mathbf{H A L}$, est destinée au dépôt et à la diffusion de documents scientifiques de niveau recherche, publiés ou non, émanant des établissements d'enseignement et de recherche français ou étrangers, des laboratoires publics ou privés. 


\section{Food Insecurity and Mental Health Problems among a Community Sample of Young Adults.}

Laura Pryor, $\mathrm{PhD}^{1}$, Sandrine Lioret, $\mathrm{PhD}^{2}$, Judith van der Waerden, $\mathrm{PhD}^{1}$, Éric Fombonne, $\mathrm{MD}, \mathrm{PHD}^{3}$, Bruno Falissard, $\mathrm{MD}, \mathrm{PHD}^{4}$, Maria Melchior, $\mathrm{ScD}^{1}$

${ }^{1}$ Sorbonne Universités, UPMC Univ Paris 06, INSERM, Institut Pierre Louis d'épidémiologie et de Santé Publique (IPLESP UMRS 1136), 75013, Paris, France

${ }^{2}$ INSERM, UMR1153 Epidemiology and Statistics Sorbonne Paris Cité Research Center (CRESS), early ORigins of Child Health And Development Team (ORCHAD), Villejuif, F-94807 France; ParisDescartes University, France

${ }^{3}$ Institute for Development \& Disability, Oregon Health \& Science University, Portland, Oregon, USA.

${ }^{4}$ INSERM U669, Université Paris-Sud and Université Paris-Descartes, Paris, France

\section{Corresponding Author:}

Laura Pryor

Social Epidemiology Research Group (ERES)

Pierre Louis Institute for Epidemiology and Public Health (iPLESP)

INSERM UMR_S 1136 \& Sorbonne Universities- Pierre et Marie Curie

27, rue Chaligny

Paris, France

75012

Tel:+ $33(0) 145595131$.

email: laura.pryor@inserm.fr

Word Count: 4015

Acknowledgments: The authors wish to thank the GAZEL study team for help in implementing the TEMPO cohort, the TEMPO participants who made this study possible, Ms. Aude Chollet for her role in coordinating and managing TEMPO study data, as well as Ms. Jeanna-Eve Franck for her statistical consulting.

The first author obtained a postdoctoral research grant from France's national health and medical research institution, INSERM (Institut National de la santé et de la recherché médicale), in order to complete the present work, including its design and conduct, analysis and interpretation of data, and the preparation and submission of the manuscript for publication. 


\begin{abstract}
Purpose: Food insecurity has been found to be related to anxiety and depression; however the association with other psychiatric disorders, particularly among young adults, is not well known. We examined whether food insecurity is independently associated with four common mental health problems among a community sample of young adults in France.

Methods: Data are from the TEMPO longitudinal cohort study. In 1991, participants' parents provided information on health and family socioeconomic characteristics. In 2011, participants' (1835 years) reported food insecurity, mental health symptoms, and socioeconomic conditions $(n=1214)$. Mental health problems ascertained included major depressive episode, suicidal ideation, attention deficit and hyperactivity disorder, and substance abuse and/or dependence (nicotine, alcohol and cannabis). Cross-sectional associations between food insecurity and mental health problems were tested using modified Poisson regressions, weighted by inverse probability weights (IPW) of exposure. This makes food-insecure and not food-insecure participants comparable on all characteristics including socioeconomic factors and past mental health problems.
\end{abstract}

Results: $8.5 \%$ of young adults were food insecure. In IPW-controlled analyses, food insecurity was associated with increased levels of depression $(R R=2.01,95 \%$ CI 1.01-4.02), suicidal ideation ( $R R=$ 3.23, 95\% CI 1.55-6.75) and substance use problems ( $\mathrm{RR}=1.68,95 \%$ CI 1.15-2.46).

Conclusions: Food insecurity co-occurs with depression, suicidal ideation and substance use problems in young adulthood. Our findings suggest that reductions in food insecurity during this important life period may help prevent mental health problems. Policies aiming to alleviate food insecurity should also address individuals' psychiatric problems, to prevent a lifelong vicious circle of poor mental health and low socioeconomic attainment.

Keywords: Food insecurity, Mental health, Substance use, Young adulthood, Social inequalities. 


\section{INTRODUCTION}

Food insecurity refers to the lack of physical or economic access to sufficient, safe, or nutritious food in order to maintain a healthy and active lifestyle [1]. Affecting 5-15\% of households in developed countries[2,3], it is a situation that is thought to have worsened since the recent economic crisis [4]. In addition to the potential for adverse physical health outcomes [5], the role of food insecurity in mental ill health has been suggested [6-8]. For instance, women who experience food insecurity have an increased prevalence of mood disorders, while children have increased rates of behavioral problems $[9,6]$. Food insecurity has also been linked to substance use problems in adolescence[7] and suicidal ideation in adulthood [10].

Food insecurity is closely linked to socioeconomic status (SES) and can be considered a marker of extreme material deprivation [7]. Yet food insecurity is also a situation that has been shown to have distinct effects on health, notably because of high levels of stress and impaired nutrition. Research on the mental health impacts of food insecurity can therefore help gain a better understanding of the subjective experiences of those affected by food insecurity as well as guide policies which aim to prevent the onset of psychiatric disorders.

Despite high prevalence, studies regarding the health impact of food insecurity have mainly focused on high-risk populations and little work has examined young adults in community samples. Young adulthood represents an important developmental period to study food insecurity, as it is often characterized by significant changes in living and occupational situation, which may place individuals in a vulnerable position. A recent nationally representative study of adults aged 18-79 years identified an inverse relationship between age and household food insecurity, with younger adults more often reporting this problem [3]. Moreover, the onset of mental health problems is also quite frequent in young adulthood [11], and food insecurity may be a predisposing factor. 
The aim of this study was to examine, among a community sample of young adults, whether there exists an independent association between food insecurity and four frequent mental health problems: depression, symptoms of inattention and hyperactivity, suicidal ideation and substance abuse and dependence. We hypothesized that, controlling for past mental health problems, parent mental health problems and past and present SES indicators, food insecurity would remain associated with psychological and substance use difficulties in young adulthood.

\section{METHODS}

Data were drawn from the French TEMPO (Trajectoires Épidémiologiques en Population) cohort. As part of the GAZEL epidemiological study, a longitudinal follow-up of 20624 employees of France's national gas and electrical company, parents provided, in 1991, information on child health and family socioeconomic characteristics. This initial sample of 2498 children (4-16 years) was selected to represent children in France in terms of key socio-demographic characteristics. In 2009, these youths were invited for a follow-up (TEMPO cohort). In 2011, 1214 young adults aged 18-35 years described their mental health symptoms and living conditions, including food insecurity experiences, in a telephone interview. As compared to young adults of the same age in France, participants in 2011 were slightly more likely to live with a partner, to have attended postsecondary education and hold a managerial job. However, the rate of lifetime unemployment was comparable to the general population [12]. Ethics approval was obtained from France's national committees for data protection [12].

It is important to note that various conceptualizations for what constitutes young adulthood exist $[11,13]$, and several scholars agree that setting limits for developmental periods in terms of age range is somewhat arbitrary $[13,14]$. Following other researchers $[15,16]$, we define young adulthood as extending from the late teens to the mid-thirties. 


\section{Measures}

Independent Variable

Food insecurity was ascertained using three questions, modified from the Cornell-Radimer Hunger Scale [17] and the USDA 10-item questionnaire [18]: Over the past 12 months, have you had financial difficulties in: 1) Eating adequately (you had to reduce portions or number of meals)?; 2) Eating balanced meals?; and 3) Eating varied meals (you had to eat the same thing several times)? For each item, participants answered "yes" or "no". These items have previously been used in population studies $[19,20]$. As in prior studies, participants reporting at least one affirmative response were classified as having experienced food insecurity $(=1)$ vs. not $(=0)$.

\section{Dependent Variables}

Past-year depression was measured using the Mini-International Neuropsychiatric Interview. Participants responded yes or no to 14 items, and were categorized as having experienced a major depressive episode $(=1)$ or not $(=0)$ in the past year if they responded "yes" to at least 5 symptoms items, in addition to one measure ascertaining whether symptoms caused impairment. Symptoms of inattention and hyperactivity were measured using the Adult Attention Deficit Hyperactivity Disorder (ADHD) Self-Report Scale 6-item screener. Each item was scored on a range from never $(=0)$ to very often (=4) and then categorized as representing, or not, a symptom of ADHD (cut-off values varied by item, from "sometimes" to "often" responses)[21]. Symptoms were summed for a score ranging from 0 to 6 . A categorical variable was created with $0=0-3$ symptoms and $1=4-6$ symptoms, corresponding to a symptom level approaching clinical diagnosis.

The following question, drawn from the Monitoring the Future Study, was used to assess suicidal ideation: “'Have you thought of suicide in the preceding 12 months?”[22] Participants were categorized as having had suicidal thoughts $(=1)$ vs. not $(=0)$. 
Substance use problems were defined as the presence of at least one of the following over the past 12 months: 1) Tobacco dependence; 2) Alcohol abuse and/or dependence or 3) Cannabis abuse and/or dependence. Participants who responded yes to smoking at least one cigarette per day were screened for nicotine dependence using the 5-item Fagerström Test for Nicotine Dependence (FTND)[23]. As per test authors' guidelines, all items were summed, yielding a score of 0 to 10 . Participants with a score greater than 2 were considered nicotine dependent and categorized as dependent (=1) vs. not (=0). Alcohol abuse and/or dependence was assessed using the French version of the Alcohol Use Disorders Identification Test (AUDIT), a 10-item questionnaire developed by the World Health Organization to match DSM-IV criteria, and validated against clinical diagnosis [24,12]. All 10 items were summed, yielding a score ranging from 0 to 20. Following published guidelines, a score $\geq 8$ in men and $\geq 7$ in women was considered indicative of alcohol abuse or dependence (=1) vs. no abuse or dependence $(=0)$ [24]. Cannabis abuse or dependence was assessed with the 8-item Cannabis Abuse Screening Test (CAST)[25]. The items included: "Do you smoke cannabis in the morning before going to school or work?", "Do you smoke cannabis when alone?", "Do you find it difficult to spend a day without smoking cannabis?", "Have you driven a car or a motor bike after smoking cannabis?", "Have you had memory problems after using cannabis?”. Total scores ranged from 0 to 8 . As recommended by test authors', cannabis abuse or dependence was defined as a score $\geq 2(=1$, vs. no abuse/dependence $=0)[25,26]$.

Variables used to Estimate Food Insecurity Propensity Score

Participants' 1) childhood and family background and 2) social, economic and living situation characteristics, potentially related to both food insecurity and mental health outcomes, were controlled for using the propensity score technique.

\section{Participants' Childhood and Family Background Variables}

Low family income (1989 and 2002) categorized families who were below (vs. above) the French median income level in 1989 and/or 2002 (approximately 2000 euros monthly). Parent alcohol 
abuse or dependence (1992-2011) as well as depression (1989-2011) were reported by parents and TEMPO participants (2009 and 2011) and considered present if reported by either source. Mean parent Body Mass Index was calculated from 15 self-report data points from 1997- 2011. Childhood violence and neglect, as well as past behavioral problems were reported by participants in 2011. Early internalizing and externalizing symptoms and thought problems were reported by parents in 1991 using the Child Behavior Checklist [27]. T-scores above the $85^{\text {th }}$ percentile were considered high.

\section{Participants' Social, Economic and Living situation}

In 2011, participants reported the following in their household (over the past 12 months): Age and sex, pregnancy/birth, single-parent status, stable job vs. short-term contracts, lifetime unemployment, overdrawn bank account, financial aid, financial difficulties paying for rent/medical care, main activity (paid work, student, looking for work, without work/not looking), educational level ( $0=$ =postsecondary; $1=$ high school; $2=$ no diploma), occupational grade and income level category. Poverty status was defined according to French guidelines, using the modified-OECD method. Social network size was classified using the French version of the Berkman-Syme Social Network Index [28]. Early smoking and cannabis initiation were categorized respectively as $<13$ years and $<15$ years. Finally, a sum of eight negative life events was included, based on the following items: Over the past 12 months, have you: Had a miscarriage or a voluntary termination of pregnancy?; Separated from your partner?; Had someone close to you suffer from a serious illness or pass away?; Been the victim of another's violent behaviors?; Been robbed, or something that belonged to you was ruined or stolen?; Been insulted or verbally harassed? Been unjustly and repeatedly criticized by someone (for ex: due to your physical appearance, dress, ideas, and opinions)? Received malicious calls, texts, and letters or internet messages?

\section{Statistical Analyses}

Analyses were conducted using SAS version 9.3. Given the complex nature of food insecurity and its inextricable link with socioeconomic factors, we used the propensity score (PS) method to balance characteristics of food-insecure and non-food-insecure participants. First we calculated the 
propensity score, indicating the probability an individual would be food insecure in 2011 given the risk factors described above ( $n=1115$ ). This was truncated slightly (for a final sample size of $n=1109$ ) at the upper end of the distribution in order to maintain overlap in propensity score values between those who had ( $n=94)$ or had not experienced food insecurity $(n=1015)$.

Based on propensity scores (PS) of food insecurity, we calculated inverse probability weights (IPW) using the equation $I P W=1 / P S$ for those who were food insecure and $I P W=1 / 1-P S$ for those who were not [29]. These were normalized and the maximum IPW was set at the value of the $99^{\text {th }}$ percentile IPW (6.97) in order to avoid including excessively high weights in subsequent analyses. The IPW method serves to approximate a random exposure allocation to the independent variable in observational data (here food insecurity) by creating a "pseudo-population" where the independent variable and covariates are not correlated $[29,12]$. In our analytical sample, we verified that the distribution of each risk factor among the food insecure and non-food insecure groups were made comparable after applying the IPWs.

Associations between food insecurity and each of depression, suicidal ideation, ADHD, and substance abuse were tested using modified Poisson regression models with robust error variance analyses [30] which make it possible to estimate relative risks. We chose this method over logistic regression because our study outcomes were not rare; this approach has also been shown to perform better than binomial or regular Poisson regression [30]. Additionally we studied the occurrence of at least one mental health problem. Bivariate and multivariate (IPW-weighted) analyses were performed.

A total of $6 \%$ of all values were missing. Results imputing missing data were similar to those obtained using the complete sample, which we present here.

In supplementary analyses, substance use outcomes (nicotine, alcohol and cannabis abuse/dependence) were examined individually. Additionally, we performed subgroup analyses, 
testing whether associations between food insecurity and mental health varied according to participants' sex and age group (<vs. $>=30$ years $)$.

\section{RESULTS}

Characteristics of the TEMPO sample according to food insecurity status are shown in

Table 1. 
Table 1. Sociodemographic characteristics of sample $(n=1109)$

\begin{tabular}{|c|c|c|c|c|c|c|c|c|}
\hline & & & & & & & \multicolumn{2}{|l|}{ p-value } \\
\hline & & & \multicolumn{2}{|c|}{$\begin{array}{l}\text { Food insecure } \\
(n=94)\end{array}$} & \multicolumn{2}{|c|}{$\begin{array}{l}\text { Not food insecure } \\
(n=1015)\end{array}$} & $\mathrm{x}^{2}$ test $^{\mathrm{a}}$ & Missing \\
\hline & & & $\mathbf{n}$ & $\%$ & $\mathbf{n}$ & $\%$ & & \\
\hline \multicolumn{2}{|c|}{ Female } & & 62 & 66.0 & 629 & 62.0 & 0.45 & $\mathbf{0}$ \\
\hline \multirow{4}{*}{$\begin{array}{l}\text { Past- } \\
\text { year: }\end{array}$} & Depression & & 14 & 14.9 & 58 & 5.7 & 0.0005 & $\mathbf{0}$ \\
\hline & $\begin{array}{l}\text { Suicidal } \\
\text { ideation }\end{array}$ & & 11 & 11.7 & 40 & 3.9 & 0.0006 & $\mathbf{0}$ \\
\hline & \multicolumn{2}{|c|}{ Inattention/hyperactivity symptoms } & 13 & 13.8 & 58 & 5.7 & 0.002 & $\mathbf{0}$ \\
\hline & \multicolumn{2}{|c|}{ Substance abuse/dependence } & 36 & 38.3 & 171 & 16.8 & $<.0001$ & $\mathbf{0}$ \\
\hline \multicolumn{2}{|c|}{ Single Parent } & & 9 & $\mathbf{1 0 . 0}$ & 15 & 1.5 & $<.0001$ & $\mathbf{0}$ \\
\hline \multicolumn{9}{|c|}{ Education level } \\
\hline & \multicolumn{2}{|c|}{ Less than high school diploma } & 13 & 13.8 & 43 & 4.2 & \multirow[t]{3}{*}{$<.0001$} & \multirow[t]{3}{*}{$\mathbf{0}$} \\
\hline & \multicolumn{2}{|c|}{ High school diploma } & 19 & 20.2 & 108 & 10.6 & & \\
\hline & \multicolumn{2}{|c|}{ Greater than high school diploma } & 62 & 66.0 & 864 & 85.1 & & \\
\hline
\end{tabular}




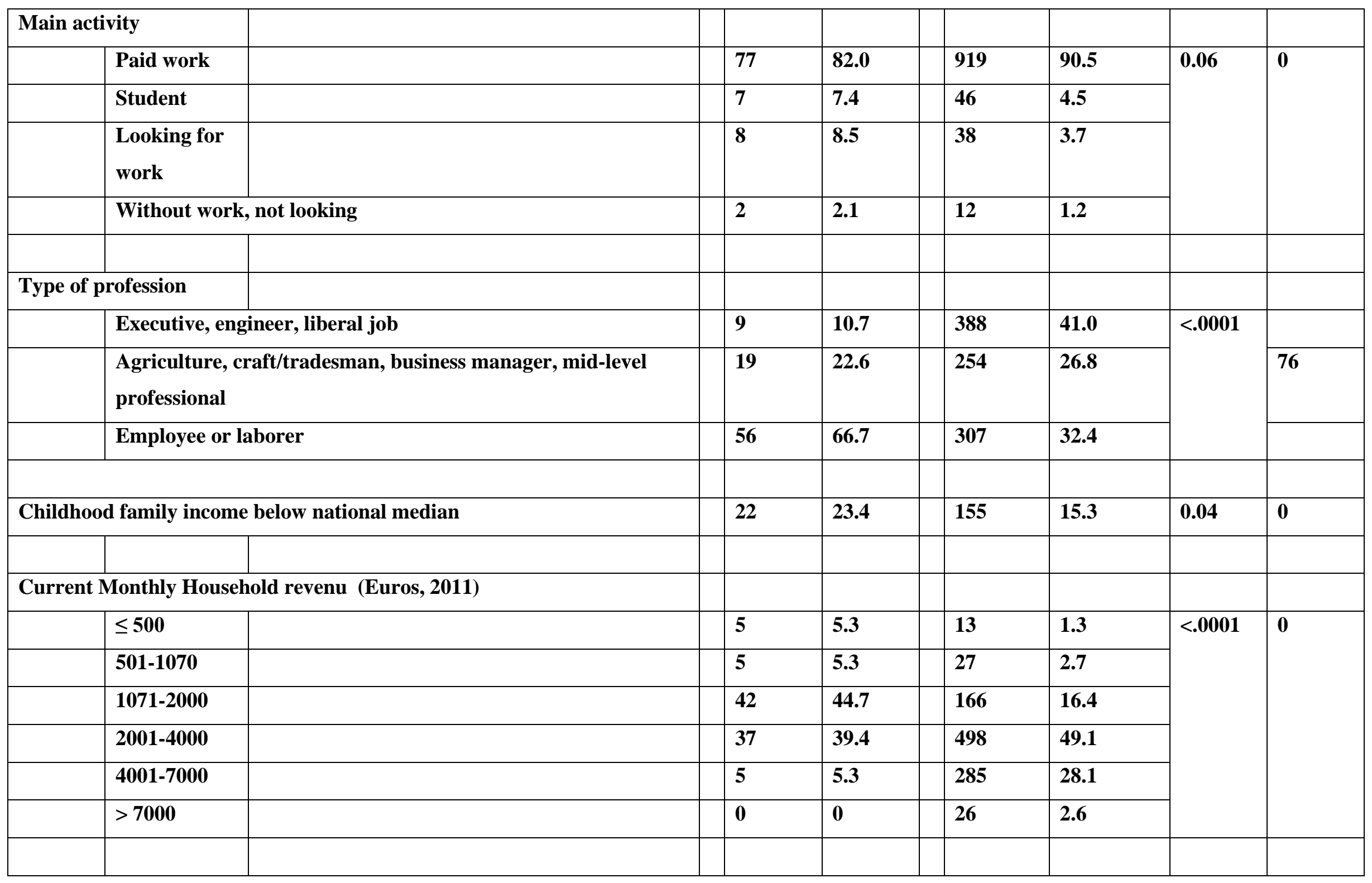




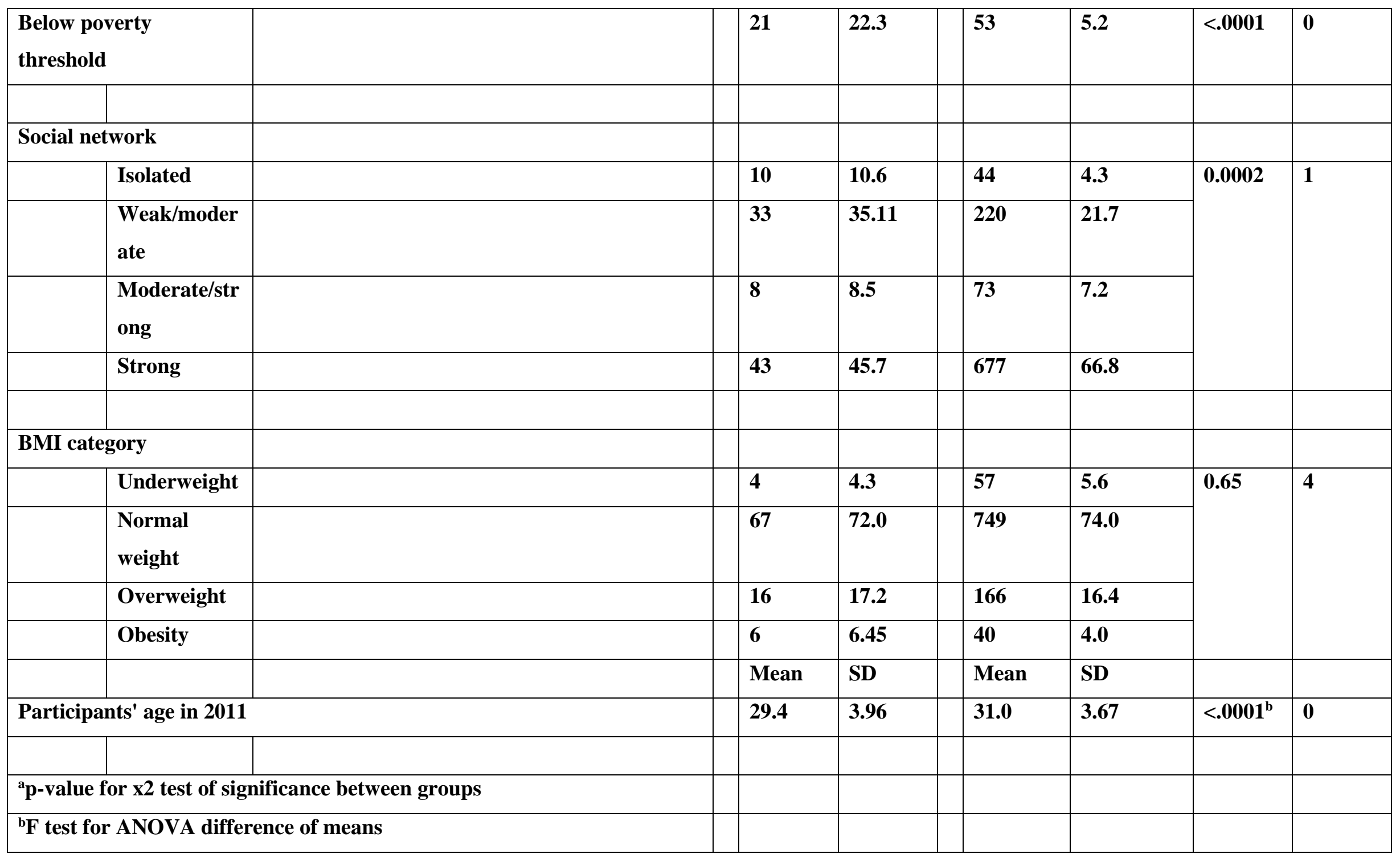


Each mental health and substance use problem analyzed was associated with food insecurity in bivariate analyses, with relative risks (RR) in the range of 2 to 3 (Table 2). In multivariate analyses, the RRs decreased, with the exception of the association between food insecurity and suicidal ideation, wherein the association became stronger (IPW weighted $\mathrm{RR}=3.23,95 \% \mathrm{CI}=1.55 ; 6.75$ ).

\begin{tabular}{|l|l|l|l|l|l|l|l|l|}
\hline $\begin{array}{l}\text { Table 2. Modified Poisson Regression Analyses of the Association between Food Insecurity and } \\
\text { Mental Health Problems (n=1109) }\end{array}$ \\
\hline & \multicolumn{2}{|l|}{ Bivariate } & \multicolumn{3}{l|}{ Multivariate } \\
\hline
\end{tabular}

${ }^{\text {a}}$ Weighted by inverse probability weight truncated at 99 th percentile.

When analyzing substance use outcomes separately, all bivariate associations between food insecurity and substance use were statistically significant (Table 3). In multivariate analyses, these RRs were reduced but remained statistically significant for alcohol abuse/dependence: $(\mathrm{RR}=1.71,95 \%$ CI 1.01-2.89) and cannabis abuse/dependence ( $R R=2.58,95 \%$ CI 1.31-5.05) (Table 3).

Table 3. Modified Poisson Regression Analyses of the Association between Food Insecurity and type of substance use problem $(n=1109)$

\begin{tabular}{|c|c|c|c|c|c|c|c|c|}
\hline & \multicolumn{4}{|c|}{ Bivariate } & \multicolumn{4}{|c|}{$\underline{\text { Multivariate }}^{\mathrm{a}}$} \\
\hline \multirow{2}{*}{$\begin{array}{l}\text { Outcome } \\
\text { Smoking }(\mathrm{n}=77)\end{array}$} & \multirow{2}{*}{$\begin{array}{l}\mathbf{R R} \\
2.65\end{array}$} & \multicolumn{2}{|l|}{ CI } & \multirow{2}{*}{$\begin{array}{l}\text { p- } \\
\text { value } \\
<.0001\end{array}$} & \multirow{2}{*}{$\begin{array}{l}\mathbf{R R} \\
1.38\end{array}$} & \multicolumn{2}{|l|}{ CI } & \multirow{2}{*}{$\begin{array}{l}\begin{array}{l}\text { p- } \\
\text { value }\end{array} \\
0.3639\end{array}$} \\
\hline & & 1.66 & 4.22 & & & 0.69 & 2.77 & \\
\hline Alcohol (n=122) & 2.07 & 1.01 & 2.89 & 0.0002 & 1.71 & 1.01 & 2.89 & 0.0445 \\
\hline Cannabis $(\mathrm{n}=59)$ & 2.81 & 1.31 & 5.05 & 0.0002 & 2.58 & 1.31 & 5.05 & 0.0059 \\
\hline
\end{tabular}

${ }^{\mathrm{a}}$ Weighted by inverse probability weight truncated at 99 th percentile. 
When analyses were conducted separately by sex, multivariate associations with food insecurity were significant among males only: depression $(\mathrm{RR}=2.99,95 \% \mathrm{CI} 1.08 ; 8.25$ for males vs. $1.42,95 \%$ CI $0.60 ; 3.39$ among females); suicidal ideation (RR=5.73, 95\% CI 1.99; 17.82 for males vs. $1.82,95 \%$ CI $0.64 ; 5.18$ for females).

Additional analyses separating participants ( $<30$ years of age vs. $>=30$ years of age) revealed that food insecurity was associated with suicide $(\mathrm{RR}=4.4,95 \% \mathrm{CI} 1.61 ; 12.35)$ and cannabis abuse/dependence within the younger group ( $\mathrm{RR}=2.98,95 \%$ CI $1.14 ; 7.80)$. Within the older group, food insecurity was associated with depression $(\mathrm{RR}=2.87,95 \% \mathrm{CI} 1.29 ; 6.35)$. 


\section{DISCUSSION}

In our study based on a community sample of young adults, we found that food insecurity increases the risk of suicidal ideation, depression and substance use, even when controlling the analysis for characteristics that make food insecure and non-food insecure youths different, including indicators of socioeconomic status (SES). This study adds to the current literature on health and social risks that young adults are exposed to and suggests that this demographic group deserves attention from researchers and health professionals.

When properly specified, IPWs adjust for confounding by creating a pseudo-population wherein all individuals have the same probability of being exposed and unexposed [29]. Weighting the analyses by our calculated IPWs led to a decrease in the relative risks for the association between food insecurity and each of depression, ADHD and substance use problems (as compared to bivariate associations), indicating part of the true association between food insecurity and these problems is likely due to common underlying social and economic factors. However, the value of the relative risk for the association between food insecurity and suicidal ideation increased when confounding was minimized by IP weighting, suggesting the true association between food insecurity and suicidal ideation is not confounded by these factors.

Low SES is a fundamental cause of ill health [31,32], limiting an individual's resources and increasing vulnerability to a disproportionate number of risk factors [32,33]. The chronic stress associated with living in poverty has repeatedly been shown to have detrimental effects on mental health through various potential pathways [34-36]. As a proxy for extreme low SES and material deprivation, food insecurity may affect mental health through some of the same pathways hypothesized for low SES more generally. However, we identified associations between food insecurity and each of depression, suicidal ideation and substance use while taking several aspects of SES into account. This suggests food insecurity may be independently linked to these outcomes during young adulthood, in line with some of the current literature among adolescents [7] and adults [10]. 
Several past studies have revealed associations between food insecurity and depression [37,8,38]. A 3-year longitudinal study by Heflin and colleagues [37] identified that among low-income women receiving welfare, food insufficiency increased the likelihood of reporting clinically significant major depression, while controlling for depression risk factors and time-invariant traits affecting both food insufficiency and mental health. Fewer studies have examined the association between food insecurity and suicidal ideation or substance use problems. Our results concur with Alaimo and colleagues [38], who identified a significant association between food insecurity and adolescent thoughts of death $(\mathrm{OR}=2.0)$ and desire to die $(\mathrm{OR}=3.4)$, as well as Davison et al. [10] who found that suicidal ideation was significantly associated with moderate $(\mathrm{OR}=1.3)$ and severe $(\mathrm{OR}=1.8)$ food insecurity among Canadian adults. However, when subgroup analyses were performed by sex, our results differed from the aforementioned study by Alaimo and colleagues [38], who identified female adolescents as being more likely than male adolescents to have had both suicidal and depressive symptoms. We identified a significant association between food insecurity and each of depression and suicidal ideation among male, but not female, young adults. The differences found may be due to the differing measures of suicidal risk or the different age range of our samples (Alaimo et al. studied adolescents, while we studied young adults).

In addition, we identified different associations by age group. Within the younger group (younger than 30 years), there was a significant association between food insecurity and both suicidal ideation and cannabis use/dependence, while within the older group, the link with depression was significant. With regards to cannabis, this finding is in line with the fact that use is more frequent at younger ages[39] and may represent a more common outcome for those younger individuals living in precarious situations. With regards to depression and suicidal ideation, past studies have identified associations with food insecurity among both adolescents and adults, $[37,8,38,7]$ however differences by age have rarely been systematically examined. Given this, and the fact that our tests were exploratory and not formal tests of interaction, further studies would be required to identify which factors may be specific to adolescence, young adulthood, and adulthood, as well as whether these are specific to men or women. 
To our knowledge, we are the first to report the association between food insecurity and young adults' substance use problems such as alcohol or cannabis addiction. Research shows that abuse of these two psychoactive products is increasingly a concern among youths in many countries, particularly as some youths do not desist from such addictive behaviors upon adopting adult social roles. Our study suggests that food insecurity may contribute to a lasting vicious circle of addiction and social exclusion.

Mechanisms underlying the potential association between food insecurity and mental health problems have thus far centered on stress and nutrition. In qualitative research studies with individuals experiencing financial hardship and food insecurity, these situations are described as extremely stressful, frustrating, and depressing [40]. They take a toll on an individual's dignity and sense of self-worth [40]. Individuals may internalize the societal stigma associated with the situation of not being able to provide adequate nutrition for themselves, or in particular, their children[41] and this may contribute to the stress pathways linking food insecurity with poor mental health.

With regards to nutrition, it has been demonstrated that individuals experiencing food insecurity must often rely on low-nutrient, calorie-dense foods [3,42,43]. A recent study of French adults [3] has identified a significantly poorer overall diet quality among food insecure individuals, with a higher consumption of sweet foods and a lower consumption of fruits, vegetables and fish. A greater risk for iron deficiency anemia among women has been found $[44,45]$. Reduced intake of certain nutrients, in turn, has been linked to irritability, nervousness, depression, and dementia, among others problems [37]. When calorie restriction occurs, this has been shown to increase cortisol secretion and amplify stress reactivity, which further predisposes to mental health problems [7] citing $[46,47]$.

Although we considered in this article that food insecurity may have a detrimental role on mental health, previous literature informs us that certain mental health problem symptoms also have a role in the onset of food insecurity [9,48], that a bidirectional association may exist [49], or that both food insecurity and mental health reflect preexisting common causes. Since the present study is crosssectional, we cannot establish the causal direction between food insecurity and the presence of mental 
health and substance use problems during young adulthood. Certain outcomes we analyzed were likely present earlier in the lives of these individuals. For example, substance use problems occur disproportionately among individuals with low income, as a means of coping with stressful life situations or linked to the existence of present-oriented behavior and a difficulty prioritizing longerterm health goals [50]. The presence of such problems could play a role in food insecurity, particularly due to the strain on economic resources that is incurred. As another example, an individual with prior depression symptoms may be predisposed to experiencing food insecurity due to organizational difficulties related to these symptoms, which include a lack of energy and an ability to make decisions [9].

Nonetheless, we controlled for prior mental health problems and other juvenile characteristics as much as possible, and the association we report is net of the effects of these factors. Therefore, it is likely that the experience of food insecurity influences the onset or the persistence of frequent mental health problems such as depression, suicidality and substance abuse.

Our results have several implications for public health. Policies geared towards providing income assistance to young adults who are in situations of food insecurity could help prevent mental health problems during this particular at-risk period [51]. Actions aiming to reduce the presence of food insecurity should also address individuals' potential mental health problems which may have contributed to the occurrence or persistence of food insecurity. To the extent that food insecurity has an impact on mental health problems through nutritional mechanisms, there is need to ensure access to sufficient and nutritious food during the young adulthood period. For instance, subsidized cafeterias in higher education institutions and workplaces may help some young adults access healthy, balanced and nutritious meals. Food banks may supplement the needs of the most vulnerable, although recourse to these may also play a role in the internalization of stigma and the stress that is associated with the experience of food insecurity [52]. Roncarolo and colleagues [53] distinguish between traditional (based on charity; ex: food banks) and alternative (aimed at member participation, capacity and social relationships building; ex: community gardens) interventions, the latter being possibly better in terms of nutrition, social inclusion and potentially mental health [52]. More work is needed in order to 
analyze how alternative interventions (or a combination) could provide sustainable solutions to improving food security among young adults. Promising results have emerged, for example the Fresh Place initiative [54], and it is crucial to investigate whether such interventions may also show improvement in participant mental health.

The main limitations of this study include the cross-sectional design of the measurement of food insecurity and mental health as well as a short (3 item) measure of food insecurity, which does not go into detail regarding the severity of the problem for the individual and their household. To the extent that this represents an increased potential for the misclassification of individuals as being food insecure who also have high levels of mental health problems, this has the potential to overestimate our results. However, statistical analyses accounted for multiple preexisting individual and family factors and the measure we used has previously been validated and is well-suited for large community samples $[19,20]$. A third limitation is that TEMPO participants have a somewhat higher socioeconomic position than the general population. This would suggest the associations between food insecurity and mental health may be stronger than we report. It is also possible that self-reported substance use measures were underreported due to factors such as social desirability, however the likelihood of this may be minimized due to the low levels of stigmatization associated with the three substances examined here, particularly in France [55]. Finally it is possible that we were not able to adequately control for all confounding variables in the calculation of our propensity score and that other underlying factors may explain part of the observed relationships.

Study strengths include the use of inverse probability weights to place food-insecure and non food-insecure individuals on an equal standing in terms of a large set of confounding variables, the use of validated measures of frequent mental health and substance abuse obtained in interviews, and our ability to study food insecurity and mental among a community sample of young adults, a group that is hard to reach when not enrolled in higher education and rarely studied [13]. 


\section{CONCLUSION}

Our study contributes to research linking food insecurity to mental health, extending prior knowledge on this topic to young adults and adding data on substance abuse. Our findings suggest that efforts to reduce food insecurity in young adults could help prevent the presence of mental health problems. Additionally, interventions addressing the needs of individuals who are food insecure should not neglect mental health problems which can fuel a long-term circle of poverty and ill health. 
Conflict of Interest Statement: On behalf of all authors, the corresponding author states that there is no conflict of interest. 


\section{REFERENCES}

1. United Nations World Food Programme: What is food security? (2015). https://www.wfp.org/node/359289.

2. Coleman-Jensen A, Gregory C, Singh A (2014) Household Food Security in the United States in 2013. United States Department of Agriculture.

3. Bocquier A, Vieux F, Lioret S, Dubuisson C, Caillavet F, Darmon N (2015) Socio-economic characteristics, living conditions and diet quality are associated with food insecurity in France. Public Health Nutr:1-10. doi:10.1017/S1368980014002912

4. Loopstra R, Reeves A, Stuckler D (2015) Rising food insecurity in Europe. Lancet 385 (9982):2041. doi:10.1016/S0140-6736(15)60983-7

5. Eisenmann JC, Gundersen C, Lohman BJ, Garasky S, Stewart SD (2011) Is food insecurity related to overweight and obesity in children and adolescents? A summary of studies, 1995-2009. Obesity reviews : an official journal of the International Association for the Study of Obesity 12 (5):e73-83. doi:10.1111/j.1467-789X.2010.00820.x

6. Whitaker RC, Phillips SM, Orzol SM (2006) Food insecurity and the risks of depression and anxiety in mothers and behavior problems in their preschool-aged children. Pediatrics 118 (3):e859-868. doi:10.1542/peds.2006-0239

7. McLaughlin KA, Green JG, Alegria M, Jane Costello E, Gruber MJ, Sampson NA, Kessler RC (2012) Food insecurity and mental disorders in a national sample of U.S. adolescents. Journal of the American Academy of Child and Adolescent Psychiatry 51 (12):1293-1303.

doi:10.1016/j.jaac.2012.09.009

8. Leung CW, Epel ES, Willett WC, Rimm EB, Laraia BA (2015) Household food insecurity is positively associated with depression among low-income supplemental nutrition assistance program participants and income-eligible nonparticipants. The Journal of nutrition 145 (3):622-627. doi:10.3945/jn.114.199414

9. Melchior M, Caspi A, Howard LM, Ambler AP, Bolton H, Mountain N, Moffitt TE (2009) Mental health context of food insecurity: a representative cohort of families with young children. Pediatrics 124 (4):e564-572. doi:10.1542/peds.2009-0583

10. Davison KM, Marshall-Fabien GL, Tecson A (2015) Association of moderate and severe food insecurity with suicidal ideation in adults: national survey data from three Canadian provinces. Social psychiatry and psychiatric epidemiology 50 (6):963-972. doi:10.1007/s00127-015-1018-1

11. Younes N, Chollet A, Menard E, Melchior M (2015) E-mental health care among young adults and help-seeking behaviors: a transversal study in a community sample. J Med Internet Res 17 (5):e123. doi:10.2196/jmir.4254

12. Melchior M, Chollet A, Elidemir G, Galera C, Younes N (2015) Unemployment and substance use in young adults: does educational attainment modify the association? European addiction research 21 (3):115-123. doi:10.1159/000365887

13. Arnett JJ (2000) Emerging adulthood. A theory of development from the late teens through the twenties. Am Psychol 55 (5):469-480

14. Freeman B, Kelly B, Vandevijvere S, Baur L (2015) Young adults: beloved by food and drink marketers and forgotten by public health? Health Promot Int. doi:10.1093/heapro/dav081 15. Clark TT (2014) Perceived discrimination, depressive symptoms, and substance use in young adulthood. Addict Behav 39 (6):1021-1025. doi:10.1016/j.addbeh.2014.01.013

16. Kapella MC, Berger BE, Vern BA, Vispute S, Prasad B, Carley DW (2015) Health-related stigma as a determinant of functioning in young adults with narcolepsy. PloS one 10 (4):e0122478.

doi:10.1371/journal.pone.0122478

17. Kendall A, Olson CM, Frongillo EA, Jr. (1995) Validation of the Radimer/Cornell measures of hunger and food insecurity. The Journal of nutrition 125 (11):2793-2801

18. U.S. Adult Food Security Survey Module. (2012) United States Deparment of Agriculture, Economic Research Service. 
http://www.ers.usda.gov/datafiles/Food Security in the United States/Food Security Survey Mo dules/ad2012.pdf. Accessed February 15th, 20152015

19. Enquête sociale et de santé auprès des enfants et des adolescents québécois 1999 (2002).

Collection la santé et le bien-être. Institut de la statistique du Québec, Québec

20. Étude longitudinale du développement des enfants du Québec (ELDEQ 1998-2002): Sources, justifications et modifications entre les volets 2001 (E4) et 2002 (E5) (2004). Institut de la statistique du Québec,

21. Adult ADHD Self-Report Scale-V1.1 (ASRS-V1.1) Screener from WHO Composite Inernatinal Diagnostic Interview (2003). World Health Organization,

22. LD J, P OM, J B (1995) National survey results on drug use from the Monitoring the Future Study, 1975-1994.

23. Heatherton TF, Kozlowski LT, Frecker RC, Fagerstrom KO (1991) The Fagerstrom Test for Nicotine Dependence: a revision of the Fagerstrom Tolerance Questionnaire. British journal of addiction 86

(9):1119-1127

24. Babor TF, Higgins-Biddle JC, Saunders JB, Monteiro MG (2001) AUDIT The The Alcohol Use Disorders Identification Test: Guidelines for Use in Primary Care- Second Edition. World Health Organization Department of Mental Health and Substance Dependence,

25. Legleye S, Piontek D, Kraus L (2011) Psychometric properties of the Cannabis Abuse Screening Test (CAST) in a French sample of adolescents. Drug and alcohol dependence 113 (2-3):229-235. doi:10.1016/j.drugalcdep.2010.08.011

26. Spilka S, Janssen E, Legleye S (2013) Detection of Problem Cannabis Use: The Cannabis Abuse Screening Test (CAST) Observatoire francais des drogues et des toxicomanies,

27. Achenbach T (1991) Manual for the Teacher's Report Form and 1991 Profile Department of Psychiatry. Burlington, Vermont

28. Melchior M, Berkman LF, Niedhammer I, Chea M, Goldberg M (2003) Social relations and selfreported health: a prospective analysis of the French Gazel cohort. Social science \& medicine 56 (8):1817-1830

29. Hernán M, Robins J (2016) IP weighting and marginal structural models In: Causal Inference. Chapman \& Hall/CRC, forthcoming, Boca Raton, pp 11-22

30. Zou G (2004) A modified poisson regression approach to prospective studies with binary data. American journal of epidemiology 159 (7):702-706

31. Link BG, Phelan J (1995) Social conditions as fundamental causes of disease. Journal of health and social behavior Spec No:80-94

32. Braveman P, Gottlieb L (2014) The social determinants of health: it's time to consider the causes of the causes. Public health reports 129 Suppl 2:19-31

33. Kawachi I, Subramanian SV, Almeida-Filho N (2002) A glossary for health inequalities. J Epidemiol Community Health 56 (9):647-652

34. McEwen BS, Gianaros PJ (2010) Central role of the brain in stress and adaptation: links to socioeconomic status, health, and disease. Ann N Y Acad Sci 1186:190-222. doi:10.1111/j.17496632.2009.05331.x

35. Lorant V, Deliege D, Eaton W, Robert A, Philippot P, Ansseau M (2003) Socioeconomic inequalities in depression: a meta-analysis. American journal of epidemiology 157 (2):98-112

36. Uddin M, Galea S, Chang SC, Koenen KC, Goldmann E, Wildman DE, Aiello AE (2013) Epigenetic signatures may explain the relationship between socioeconomic position and risk of mental illness: preliminary findings from an urban community-based sample. Biodemography Soc Biol 59 (1):68-84. doi:10.1080/19485565.2013.774627

37. Heflin CM, Siefert K, Williams DR (2005) Food insufficiency and women's mental health: findings from a 3-year panel of welfare recipients. Social science \& medicine 61 (9):1971-1982.

doi:10.1016/j.socscimed.2005.04.014

38. Alaimo K, Olson CM, Frongillo EA (2002) Family food insufficiency, but not low family income, is positively associated with dysthymia and suicide symptoms in adolescents. The Journal of nutrition $132(4): 719-725$ 
39. Beck F, Legleye S, Spilka S (2007) Cannabis, données essentielles. Partie 1: Consommation de cannabis : niveaux, évolution, géographie. Observatoire français des drogues et des toxiocomanies, Paris, France

40. Knowles M, Rabinowich J, Ettinger de Cuba S, Cutts DB, Chilton M (2015) "Do You Wanna Breathe or Eat?": Parent Perspectives on Child Health Consequences of Food Insecurity, Trade-Offs, and Toxic Stress. Matern Child Health J. doi:10.1007/s10995-015-1797-8

41. Tarasuk VS, Beaton GH (1999) Household food insecurity and hunger among families using food banks. Can J Public Health 90 (2):109-113

42. Drewnowski A, Specter SE (2004) Poverty and obesity: the role of energy density and energy costs. Am J Clin Nutr 79 (1):6-16

43. Davison KM, Kaplan BJ (2015) Food insecurity in adults with mood disorders: prevalence estimates and associations with nutritional and psychological health. Annals of general psychiatry 14:21. doi:10.1186/s12991-015-0059-x

44. Klesges LM, Pahor M, Shorr RI, Wan JY, Williamson JD, Guralnik JM (2001) Financial difficulty in acquiring food among elderly disabled women: results from the Women's Health and Aging Study. Am J Public Health 91 (1):68-75

45. Fischer NC, Shamah-Levy T, Mundo-Rosas V, Mendez-Gomez-Humaran I, Perez-Escamilla R (2014) Household food insecurity is associated with anemia in adult Mexican women of reproductive age. The Journal of nutrition 144 (12):2066-2072. doi:10.3945/jn.114.197095

46. Macht M (1996) Effects of high- and low-energy meals on hunger, physiological processes and reactions to emotional stress. Appetite 26 (1):71-88. doi:10.1006/appe.1996.0006

47. Tomiyama AJ, Mann T, Vinas D, Hunger JM, Dejager J, Taylor SE (2010) Low calorie dieting increases cortisol. Psychosom Med 72 (4):357-364. doi:10.1097/PSY.0b013e3181d9523c

48. Chilton M, Rose D (2009) A rights-based approach to food insecurity in the United States. Am J Public Health 99 (7):1203-1211. doi:10.2105/AJPH.2007.130229

49. Huddleston-Casas C, Charnigo R, Simmons LA (2009) Food insecurity and maternal depression in rural, low-income families: a longitudinal investigation. Public Health Nutr 12 (8):1133-1140.

doi:10.1017/S1368980008003650

50. Peretti-Watel P, L'Haridon O, Seror V (2013) Time preferences, socioeconomic status and smokers' behaviour, attitudes and risk awareness. Eur J Public Health 23 (5):783-788.

doi:10.1093/eurpub/cks189

51. Tarasuk V, Mitchell A, McLaren L, McIntyre L (2013) Chronic physical and mental health conditions among adults may increase vulnerability to household food insecurity. The Journal of nutrition 143 (11):1785-1793. doi:10.3945/jn.113.178483

52. Engler-Stringer R, Berenbaum S (2007) Exploring food security with collective kitchens participants in three Canadian cities. Qual Health Res 17 (1):75-84. doi:10.1177/1049732306296451 53. Roncarolo F, Adam C, Bisset S, Potvin L (2015) Traditional and alternative community food security interventions in Montreal, Quebec: different practices, different people. J Community Health 40 (2):199-207. doi:10.1007/s10900-014-9917-8

54. Martin KS, Wu R, Wolff M, Colantonio AG, Grady J (2013) A novel food pantry program: food security, self-sufficiency, and diet-quality outcomes. Am J Prev Med 45 (5):569-575.

doi:10.1016/j.amepre.2013.06.012

55. Johnson T (2014) Sources of Error in Substance Use Prevalence Surveys. International Scholarly Research Notices 2014 (923290):21 